\title{
Influência de HeRbicidas na Atividade Fotossintética de Genótipos DE CANA-DE-AÇÚCAR ${ }^{1}$
}

\author{
Influence of Herbicides on the Photosynthetic Activity of Sugarcane Genotypes
}

\author{
GALON, L. ${ }^{2}$, FERREIRA, F.A. ${ }^{3}$, SILVA, A.A. ${ }^{3}$, CONCENÇO, G. ${ }^{2}$, FERREIRA, E.A. ${ }^{4}$, \\ BARBOSA, M.H.P. ${ }^{3}$, SILVA, A.F. ${ }^{2}$, ASPIAZÜ, I. ${ }^{2}$, FRANÇA, A.C. ${ }^{2}$ e TIRONI, S.P. ${ }^{2}$
}

\begin{abstract}
RESUMO - Objetivou-se com este trabalho avaliar em campo os efeitos de herbicidas sobre a atividade fotossintética de genótipos de cana-de-açúcar. Para isso, foi realizado um experimento em blocos casualizados, em parcelas subdivididas, com quatro repetições. Nas parcelas principais alocaram-se os herbicidas ametryn $\left(2.000 \mathrm{~g} \mathrm{ha}^{-1}\right)$, trifloxysulfuron-sodium $\left(22,5 \mathrm{~g} \mathrm{ha}^{1}\right)$, a mistura de ametryn + trifloxysulfuron-sodium $\left(1.463+37,0 \mathrm{~g} \mathrm{ha}^{-1}\right)$ e uma testemunha capinada. Nas subparcelas foram avaliados seis genótipos de cana-de-açúcar (RB72454, RB835486, RB855113, RB867515, RB947520 e SP80-1816). Aos 70 dias após o plantio e 15 dias após a aplicação dos herbicidas, foram realizadas as avaliações da taxa de fluxo de gases pelos estômatos $\left(\mathrm{U}-\mu \mathrm{mol} \mathrm{s} \mathrm{s}^{-1}\right)$, concentração de $\mathrm{CO}_{2}$ subestomática $\left(\mathrm{Ci}=\mu \mathrm{mol} \mathrm{mol}^{-1}\right)$, taxa fotossintética (A - $\left.\mu \mathrm{mol} \mathrm{m}^{2} \mathrm{~s}^{-1}\right)$ e $\mathrm{CO}_{2}$ consumido $\left(\Delta \mathrm{C}-\mu \mathrm{mol} \mathrm{mol}{ }^{-1}\right)$, na primeira folha da cana-de-açúcar com a ligula visivel (dewlap visivel). O ametryn causou danos significativos nas características fisiológicas ligadas à atividade fotossintética da cana-de-açúcar, em comparação com o trifloxysulfuron-sodium. Os genótipos de cana-de-açúcar apresentam sensibilidade diferencial aos herbicidas. Os mais suscetiveis ao ametryn foram o RB835486 e RB867515, e os mais tolerantes, o RB72454, RB855113, RB947520 e SP80-1816. Quanto às características avaliadas, não se observou diferença entre os genótipos tratados com o trifloxysulfuron-sodium e a mistura de ametryn + trifloxysulfuron-sodium.
\end{abstract}

Palavras-chave: Saccharum spp., ametryn, trifloxysulfuron-sodium, IRGA.

\begin{abstract}
The objective of this study was to evaluate the effects of herbicides on the photosynthetic activity of sugarcane genotypes, under field conditions. An experiment was arranged in a randomized block design with split-plots and four replications. The following herbicides were allocated in the main plot: ametryn (2.000 $\left.\mathrm{g} \mathrm{ha}^{-1}\right)$, trifloxysulfuron-sodium $\left(22.5 \mathrm{~g} \mathrm{ha}^{-1}\right)$, mixture of ametryn + trifloxysulfuron-sodium $\left(1,463+37 \mathrm{~g} \mathrm{ha}^{-1}\right)$ and a hoed treatment without herbicide. In the subplots, six sugarcane genotypes (RB72454, RB835486, RB8551 13, RB867515, RB947520 and SP80-1816) were allocated. At 70 days after planting and 15 days after herbicide application, evaluations of stomatal gas flow rate ( $U$ - $\mu \mathrm{mol} \mathrm{s} \mathrm{s}^{-1}$ ), sub-stomatal $\mathrm{CO}_{2}$ concentration ( $\mathrm{Ci}$ - $\mu$ mol mol ${ }^{-1}$ ), photosynthetic rate $\left(A-\mu \mathrm{mol} \mathrm{m} \mathrm{s}^{-1}\right)$ and $\mathrm{CO}_{2}$ consumed $\left(\Delta \mathrm{C}-\mu \mathrm{mol} \mathrm{mol} \mathrm{m}^{-1}\right)$ were conducted on the first plant leaf with visible ligule. Ametryn caused significant damage to the physiological characteristics related to sugarcane photosynthetic activity compared to the trifloxysulfuron-sodium. Sugarcane genotypes show differential sensitivity to herbicide treatments, with the most susceptible to ametryn being $R B 835486$ and RB867515, and the most tolerant RB72454, RB855113, RB947520, SP80-1816 and $R B 867515$. Regarding the evaluated characteristics, there was no difference between the genotypes treated with trifloxysulfuron-sodium and the mixture of ametryn + trifloxysulfuron-sodium.
\end{abstract}

Keywords: Saccharum spp., ametryn, trifloxysulfuron-sodium, IRGA.

1 Recebido para publicação em 30.7.2009 e na forma revisada em 3.9.2010.

2 Engo-Agr ${ }^{0}$, Prof. da Universidade Federal do Pampa - UNIPAMPA, Campus Itaqui-RS, Rua Luiz de Joaquim de Sá Britto, s/n, 97650-000 Bairro Promorar, Itaqui-RS, <galonleandro@ig.com.br>; ${ }^{3}$ Eng ${ }^{-}-$Agr ${ }^{\circ}$, D.Sc., Prof. - DFT/UFV, Bolsista em Produtividade de Pesquisa do CNPq; ${ }^{4}$ Engo-Agro ${ }^{-}$, D.Sc., Pós-Doutorado - DFT/UFV.

Planta Daninha, Viçosa-MG, v. 27, n. 3, p. 591-597, 2009 


\section{INTRODUÇÃO}

O principal destaque da agroenergia no Brasil é a produção de etanol, proveniente da fermentação da sacarose produzida pela canade-açúcar (Embrapa, 2008). Essa cultura é a melhor opção para a produção desse combustivel do ponto de vista econômico, energético e ambiental (Andreoli \& De Souza, 2006).

Entre os fatores bióticos que limitam a produtividade da cana-de-açúcar, a interferência exercida pelas plantas daninhas, que competem por água, luz, nutrientes e espaço, pode causar perdas significativas na produtividade, na qualidade do produto colhido e também na longevidade do canavial (Kuva et al., 2003; Negrisoli et al., 2004).

O controle de plantas daninhas é prática de manejo obrigatória nos canaviais, sendo o método químico o mais utilizado em todo o território nacional, devido à sua alta eficiência, praticidade e baixo custo, se comparado aos demais métodos de controle (Christoffoleti et al., 2006; Kuva et al., 2008).

Atualmente estão registrados no Ministério da Agricultura, Pecuária e Abastecimento 42 ingredientes ativos e 189 marcas comerciais de herbicidas recomendados para a cultura da cana-de-açúcar (AGROFIT, 2008). Entre eles, destacam-se como os mais utilizados o ametryn e o trifloxysulfuron-sodium, aplicados isoladamente ou em misturas formuladas comercialmente. Na atualidade, os programas de melhoramento genético estão liberando e protegendo grande número de cultivares de cana-de-açúcar, cada vez mais produtivos, com maior resistência às doenças e pragas, existindo também a preocupação com a tolerância destas aos herbicidas. Entretanto, são poucos os trabalhos desenvolvidos com os cultivares mais modernos, que tenham relatado maior ou menor tolerância de genótipos de cana-deaçúcar a herbicidas (Oliveira et al., 2004; Ferreira et al., 2005). Além disso, são escassos os conhecimentos acerca da ação de herbicidas sobre possíveis alterações nos processos fisiológicos de diferentes clones da cana-deaçúcar. Segundo Azania et al. (2006), a aplicação de herbicidas em pós-emergência tardia sobre a cana-de-açúcar pode causar elevados indices de intoxicação, limitando a produtividade. Esses autores atribuem esse fato a mudanças fisiológicas, que podem provocar efeitos negativos na qualidade final dos colmos colhidos.

O herbicida ametryn é empregado para controle de plantas daninhas monocotiledôneas na cana-de-açúcar. Apresenta baixa toxicidade para animais e humanos (Rodrigues $\&$ Almeida, 2005) e pode ser usado em pré ou em pós-emergência inicial das plantas daninhas. Além disso, é muito utilizado em misturas com diversos herbicidas na cana-deaçúcar. Entre estas, a que mais se destaca atualmente é a mistura formulada do ametryn + trifloxysulfuron-sodium, denominada Krismat $^{\circledR}$. Esse produto é eficiente sobre dicotiledôneas, monocotiledôneas e ciperáceas (Rodrigues \& Almeida, 2005). O ametryn apresenta fácil absorção pelas raízes e pelas folhas; seus sintomas de intoxicação em canade-açúcar caracterizam-se por clorose seguida de necrose, iniciando-se pelos bordos das folhas (Velini et al., 2000). Quando utilizado em pós-emergência, os sintomas de intoxicação podem se apresentar de forma restrita ou ser mais acentuados nos pontos de contato da calda herbicida com as folhas. Segundo Barela $\&$ Christoffoleti (2006), dependendo do grau de intoxicação da necrose ocasionada no limbo foliar, poderá ocorrer redução na taxa fotossintética da planta, com consequente redução na produtividade da cultura. Todavia, esses autores não avaliaram quais processos ligados à fotossintese são mais afetados por esse herbicida e tampouco se existem diferenças entre genótipos.

Considerando que o herbicida ametryn pertence ao grupo dos inibidores do fotossistema II (FS II) na fotossintese, seus danos à cultura podem ser diretamente aferidos pela mensuração da taxa fotossintética e de variáveis associadas a ela (Silva et al., 2007). Além da interferência das plantas daninhas, da ocorrência de pragas e doenças e das condições edafoclimáticas, outros fatores podem prejudicar o crescimento e desenvolvimento da canade-açúcar, como a atividade fotossintética da cultura, que pode ser influenciada direta ou indiretamente pela deficiência hídrica, pelo estresse térmico (Loreto \& Bongi, 1989), pela concentração interna e externa de gases (Kirschbaum \& Pearcy, 1988), pela composição e intensidade da luz (Sharkey \& Raschke, 1981) 
e, principalmente, pelos danos causados pelos herbicidas (Ferreira et al., 2005; Barela \& Christoffoleti, 2006), entre outros.

A taxa fotossintética está diretamente relacionada à radiação fotossinteticamente ativa, ou seja, ao comprimento de onda de luz de 400 a 700 nanômetros, espectro de radiação que está envolvido na fotossintese, e indiretamente aos fatores relacionados, às trocas gasosas e disponibilidade hídrica (NavesBarbiero et al., 2000), sendo altamente dependente da abertura estomática. Assim, acredita-se que os herbicidas inibidores do FS II na fotossintese, como o ametryn, podem afetar esses processos. O herbicida trifloxysulfuronsodium, no entanto, por atuar inibindo a enzima acetolactato sintase (ALS), essencial para a biossíntese dos aminoácidos de cadeia ramificada (valina, leucina e isoleucina) (Rodrigues \& Almeida, 2005), pode ter seus danos às plantas avaliados pela sua influência indireta sobre as variáveis associadas à fotossintese (Taiz \& Zeiger, 2006).

Objetivou-se com este trabalho avaliar os efeitos dos herbicidas ametryn e trifloxysulfuron-sodium, aplicados de forma isolada ou em mistura formulada, sobre as características ligadas ao processo fotossintético de genótipos de cana-de-açúcar, em campo.

\section{MATERIAL E MÉTODOS}

O trabalho foi realizado no municipio de Oratórios-MG, na latitude de $20^{\circ} 20^{\prime} \mathrm{s}$ e longitude de $43^{\circ} 48^{\prime} \mathrm{W}$, em um Argissolo Vermelho-Amarelo (Embrapa, 2006). O plantio da cana-de-açúcar foi realizado em sulcos feitos após o preparo do solo pelo sistema convencional de cultivo. A adubação foi feita no momento do plantio, com base nos resultados da análise do solo (Tabela 1) e recomendações para a cultura (CFSEMG, 1999). As unidades experimentais foram representadas por 10 linhas com $10 \mathrm{~m}$ de comprimento, espaçadas de 1,40 m. Nos sulcos das unidades experimentais foram depositadas 16 gemas $\mathrm{m}^{-1}$.

O delineamento experimental foi o de blocos casualizados, com quatro repetições, em parcelas subdivididas. Nas parcelas foram alocados os herbicidas: \{ametryn $-2.000 \mathrm{~g}^{\text {ha }}{ }^{-1}$ (Metrimex $500 \mathrm{SC}^{\circledR}$ ), trifloxysulfuron-sodium 22,5 $\mathrm{g} \mathrm{ha}^{-1}\left(\right.$ Envoke $\left.^{\circledR}\right)$, a mistura formulada comercialmente ametryn + trifloxysulfuronsodium $-1.463+37,0 \mathrm{~g} \mathrm{ha}^{-1}\left(\right.$ Krismat $\left.\left.^{\circledR}\right)\right\}$ e uma testemunha sem aplicação de herbicidas (capinada). Nas subparcelas foram plantados os genótipos de cana-de-açúcar (RB72454, RB835486, RB855113, RB867515, RB947520 e SP80-1816).

A aplicação dos herbicidas foi feita em pósemergência inicial da cultura, aos 70 dias após o plantio (DAP) da cana-de-açúcar, com pulverizador costal pressurizado a $\mathrm{CO}_{2}$, munido com barra de 2,0 $\mathrm{m}$ - acoplado a esta quatro pontas de pulverização da série TT 110.02, espaçadas de $0,5 \mathrm{~m}$ - calibrado para aplicar o equivalente a $150 \mathrm{~L} \mathrm{ha}^{-1}$ de calda. No momento da aplicação, a temperatura era de $23{ }^{\circ} \mathrm{C}$ e a velocidade do vento de $5 \mathrm{~km} \mathrm{~h}^{-1}$.

Aos 85 DAP, o que correspondeu a 15 dias após aplicação dos herbicidas (DAA), foram

Tabela 1 - Análise química do solo Argissolo Vermelho-Amarelo utilizado no experimento. Oratórios-MG, 2007

\begin{tabular}{|c|c|c|c|c|c|c|c|c|}
\hline \multirow{2}{*}{\multicolumn{2}{|c|}{ Camada amostrada }} & $\mathrm{pH}$ & $\mathrm{P}$ & $\mathrm{K}^{+}$ & $\mathrm{H}+\mathrm{Al}$ & $\mathrm{Al}^{3+}$ & $\mathrm{Ca}^{2+}$ & $\mathrm{Mg}^{2+}$ \\
\hline & & $\left(\mathrm{H}_{2} \mathrm{O}\right)$ & \multicolumn{3}{|c|}{$\left(\mathrm{mg} \mathrm{dm}^{-3}\right)$} & \multicolumn{3}{|c|}{$\left(\mathrm{cmol}_{\mathrm{c}} \mathrm{dm}^{-3}\right)$} \\
\hline \multicolumn{2}{|c|}{$0-10 \mathrm{~cm}$} & 5,1 & 4,5 & 33 & 2,15 & 0,2 & 1,5 & 0,7 \\
\hline SB & CTC (t) & CTC (T) & $\mathrm{v}$ & $\mathrm{m}$ & $\mathrm{MO}$ & Argila & Areia & Silte \\
\hline \multicolumn{3}{|c|}{$\left(\mathrm{cmol}_{\mathrm{c}} \mathrm{dm}^{-3}\right)$} & \multicolumn{2}{|c|}{$(\%)$} & \multicolumn{2}{|c|}{$\left(\right.$ dag kg $\left.^{-1}\right)$} & \multicolumn{2}{|c|}{$(\%)$} \\
\hline 2,28 & 2,48 & 2,48 & 51 & 8,0 & 0,9 & 39 & 43 & 18 \\
\hline
\end{tabular}

1/ Análise realizada no Laboratório de Análise de Solos Viçosa Ltda. pH: em água, relação 1:2,5. P-K: extrator Mehlich 1. Ca-Mg e Al: extrator $\mathrm{KCl}-1 \mathrm{~mol} \mathrm{~L}^{-1} . \mathrm{H}+\mathrm{Al}$ : extrator acetato de cálcio $0,5 \mathrm{~mol} \mathrm{~L}^{-1}-\mathrm{pH} 7,0$. SB: soma de bases trocáveis. CTC (t): capacidade de troca catiônica efetiva. CTC (T): capacidade de troca catiônica a pH 7,0. v: saturação de bases. m: saturação de alumínio. MO: matéria orgânica $=$ C.org $\times 1,724-$ Walkley-Black. 
avaliados a taxa de fluxo de gases pelos estômatos $\left(\mathrm{U}-\mu \mathrm{mol} \mathrm{s}{ }^{-1}\right)$, a concentração de $\mathrm{CO}_{2}$ subestomática $\left(\mathrm{Ci}-\mu \mathrm{mol} \mathrm{mol}{ }^{-1}\right)$, a taxa fotossintética (A - $\left.\mu \mathrm{mol} \mathrm{m} \mathrm{m}^{-2} \mathrm{~s}^{-1}\right)$ e o $\mathrm{CO}_{2}$ consumido $\left(\Delta \mathrm{C}-\mu \mathrm{mol} \mathrm{mol}{ }^{-1}\right)$ pela cultura. Essas avaliações foram realizadas na primeira folha da canade-açúcar com a lígula visivel (dewlap visivel), utilizando-se analisador de gases no infravermelho (IRGA), marca ADC, modelo LCA PRO (Analytical Development Co. Ltd, Hoddesdon, UK), em campo. Nesta mesma época (15 DAA), coletou-se nas unidades experimentais, rente ao solo, a massa da matéria seca da parte aérea (g por planta $\mathrm{m}^{-1}$ ) dos genótipos, acondicionando-se o material em sacos de papel, sendo posteriormente transportados até o Laboratório de Herbicida no Solo, onde foram secos em estufa de circulação de ar forçado a uma temperatura de $70 \pm 2{ }^{\circ} \mathrm{C}$, até atingirem massa constante.

Os dados foram submetidos à análise de variância. Quando o F foi significativo, aplicou-se o teste de Duncan para avaliar tanto o efeito dos tratamentos como as diferenças de sensibilidade entre genótipos aos referidos herbicidas. Todos os testes foram efetuados a $5 \%$ de probabilidade.

\section{RESULTADOS E DISCUSSÃO}

Comparados dentro de cada tratamento, o genótipo SP80-1816 foi inferior aos demais quando isento da aplicação de herbicidas, para a variável massa da matéria seca da parte aérea (MSPA) (Tabela 2). Sob aplicação de ametryn, o RB867515 foi o que mais produziu MSPA, quando comparado aos demais genótipos. Sob efeito do trifloxysulfuron-sodium, o RB72454 acumulou mais MSPA em relação aos demais, e, com aplicação da mistura formulada de ametryn + trifloxysulfuron-sodium, os genótipos apresentaram MSPA similar. O acúmulo de massa da matéria seca das plantas não se correlacionou diretamente com as características fisiológicas estudadas (dados não apresentados), porque o crescimento da planta é uma característica resultante da acumulação de biomassa desde a emergência até o momento da avaliação, portanto, contínua, enquanto as características fisiológicas são análises pontuais e altamente dependentes das condições ambientais.
A MSPA das plantas de cana-de-açúcar, em geral, foi maior na testemunha quando comparada aos tratamentos herbicidas, exceto para o genótipo SP80-1816 (Tabela 2). De maneira geral, salienta-se a sensibilidade diferencial aos herbicidas entre os genótipos, sendo RB72454 e RB855113 os mais sensiveis ao ametryn ou à mistura formulada, e RB835486, RB867515 e RB947520, ao trifloxysulfuronsodium e também à mistura formulada. A redução no acúmulo de MSPA em função da aplicação do ametryn em aplicação isolada foi de 51,0 e $41,4 \%$, respectivamente para os genótipos RB72454 e RB855113, quando comparados à testemunha sem aplicação. Por outro lado, a redução devido ao trifloxysulfuronsodium foi de 49,6, 40,4 e 59,5\%, respectivamente para RB835486, RB867515 e RB947520, quando comparada à das respectivas testemunhas sem herbicida. Resultados semelhantes foram observados por Ferreira et al. (2005), ao avaliarem 15 genótipos de cana-de-açúcar tratados com doses de ametryn + trifloxysulfuronsodium. Esses autores constataram diferenças entre os genótipos de cana-de-açúcar estudados quanto ao acúmulo da MSPA. Reis et al. (2008), ao trabalharem com ametryn, trifloxysulfuronsodium, ametryn + trifloxysulfuron-sodium e 2,4-D, observaram que a mistura formulada de ametryn + trifloxysulfuron-sodium proporcionou menor redução da MSPA, em relação aos demais herbicidas, aos 60 DAT para o genótipo de cana-de-açúcar RB867515. Desse modo, fica evidente que há diferenciação na produção da MSPA em função do genótipo de cana-deaçúcar e do herbicida utilizado.

De maneira geral, o consumo de $\mathrm{CO}_{2}(\Delta \mathrm{C})$ pela fotossíntese no período de avaliação foi menor nos tratamentos que incluíram ametryn, isolado ou em mistura com trifloxysulfuronsodium (Tabela 2). Para os genótipos RB72454 e RB855113, somente o tratamento de ametryn aplicado isoladamente foi inferior à testemunha quanto ao consumo de $\mathrm{CO}_{2}$ pelo processo fotossintético. Quanto aos demais genótipos, com exceção do SP80-1816, o tratamento que envolveu a mistura de ametryn + trifloxysulfuron-sodium também foi menor que a testemunha, enquanto para RB835486 a aplicação de ametryn foi inferior também aos tratamentos que envolveram o trifloxysulfuron-sodium aplicado isoladamente ou em mistura. $\mathrm{O} \mathrm{CO}_{2}$ consumido está diretamente 
Influência de herbicidas na atividade fotossintética de genótipos ...

Tabela 2 - Variáveis associadas à fotossíntese em genótipos de cana-de-açúcar, avaliadas aos 85 dias após plantio (DAP) e 15 dias após aplicação (DAA) dos herbicidas

\begin{tabular}{|c|c|c|c|c|c|c|}
\hline \multirow{2}{*}{ Tratamento } & \multicolumn{6}{|c|}{ Genótipo } \\
\hline & RB72454 & RB835486 & RB855113 & RB867515 & RB947520 & SP801816 \\
\hline & \multicolumn{6}{|c|}{ Massa da matéria seca da parte aérea - MSPA ( $\mathrm{g}$ por planta) } \\
\hline $\mathrm{TC}^{1 /}$ & $5,77 \mathrm{Aa}^{2} /$ & $5,46 \mathrm{Aa}$ & $4,93 \mathrm{Aa}$ & $5,02 \mathrm{Aa}$ & $5,02 \mathrm{Aa}$ & $2,46 \mathrm{Ba}$ \\
\hline HÁ & $2,83 \mathrm{Bb}$ & 3,69 Bab & $2,89 \mathrm{Bb}$ & $5,97 \mathrm{Aa}$ & $3,38 \mathrm{Bab}$ & $3,63 \mathrm{Ba}$ \\
\hline HB & $5,21 \mathrm{Aab}$ & $2,81 \mathrm{Bb}$ & $3,81 \mathrm{Bab}$ & $2,99 \mathrm{Bb}$ & $2,03 \mathrm{Bb}$ & $2,3 \mathrm{Ba}$ \\
\hline \multirow[t]{2}{*}{$\mathrm{HC}$} & $2,90 \mathrm{Ab}$ & $1,99 \mathrm{Ab}$ & $2,46 \mathrm{Ab}$ & $2,09 \mathrm{Ab}$ & $1,66 \mathrm{Ab}$ & $1,30 \mathrm{Aa}$ \\
\hline & \multicolumn{6}{|c|}{$\mathrm{CO}_{2}$ consumido $-\mathrm{C}\left(\mathrm{mol} \mathrm{mol}^{-1}\right)$} \\
\hline $\mathrm{TC}^{1 /}$ & $124 \mathrm{Aab}$ & $149 \mathrm{ABa}$ & $120 \mathrm{Ba}$ & $139 \mathrm{ABa}$ & $177 \mathrm{Aa}$ & $117 \mathrm{Ba}$ \\
\hline HA & $109 \mathrm{Ab}$ & $75 \mathrm{Bc}$ & $105 \mathrm{ABb}$ & $91 \mathrm{ABb}$ & $102 \mathrm{ABb}$ & $110 \mathrm{Aa}$ \\
\hline HB & $119 \mathrm{ABab}$ & $106 \mathrm{Bb}$ & $114 \mathrm{ABab}$ & $118 \mathrm{ABab}$ & $144 \mathrm{Aab}$ & $108 \mathrm{Ba}$ \\
\hline \multirow[t]{2}{*}{$\mathrm{HC}$} & $131 \mathrm{Aa}$ & $107 \mathrm{Ab}$ & $112 \mathrm{ABab}$ & $95 \mathrm{Ab}$ & $118 \mathrm{Ab}$ & $111 \mathrm{Aa}$ \\
\hline & \multicolumn{6}{|c|}{ Fluxo de Gases pelos Estômatos - U ( $\left.\mathrm{mol} \mathrm{s}^{-1}\right)$} \\
\hline $\mathrm{TC}^{\underline{1}}$ & $198,9 \mathrm{Aa}$ & $199,0 \mathrm{Aa}$ & $199,7 \mathrm{Aa}$ & $198,7 \mathrm{Aa}$ & $198,7 \mathrm{Aa}$ & $198,8 \mathrm{Aa}$ \\
\hline HA & $199,0 \mathrm{Aa}$ & $198,7 \mathrm{Aa}$ & $199,2 \mathrm{Aa}$ & $198,8 \mathrm{Aa}$ & $198,7 \mathrm{Aa}$ & $198,8 \mathrm{Aa}$ \\
\hline HB & $199,0 \mathrm{Aa}$ & $198,7 \mathrm{Aa}$ & $199,5 \mathrm{Aa}$ & $199,0 \mathrm{Aa}$ & $200,7 \mathrm{Aa}$ & $199,5 \mathrm{Aa}$ \\
\hline \multirow[t]{2}{*}{$\mathrm{HC}$} & $198,8 \mathrm{Aa}$ & $200,1 \mathrm{Aa}$ & $199,2 \mathrm{Aa}$ & $198,8 \mathrm{Aa}$ & $199,0 \mathrm{Aa}$ & $198,7 \mathrm{Aa}$ \\
\hline & \multicolumn{6}{|c|}{ Concentração interna de $\mathrm{CO}_{2}-\mathrm{Ci}\left(\mathrm{mol} \mathrm{mol}^{-1}\right)$} \\
\hline $\mathrm{TC}^{\underline{1 /}}$ & $102,0 \mathrm{ABb}$ & $177,0 \mathrm{Aa}$ & $104,5 \mathrm{ABb}$ & $123,5 \mathrm{ABb}$ & $68,3 \mathrm{Bc}$ & $120,3 \mathrm{ABb}$ \\
\hline HA & $165,2 \mathrm{Aa}$ & $136,0 \mathrm{Aab}$ & $169,5 \mathrm{Aa}$ & $178,0 \mathrm{Aa}$ & $134,0 \mathrm{Aa}$ & $157,5 \mathrm{Aa}$ \\
\hline HB & $126,5 \mathrm{ABab}$ & $127,5 \mathrm{ABab}$ & $128,0 \mathrm{ABab}$ & $114,3 \mathrm{ABb}$ & $87,7 \mathrm{Bb}$ & $137,3 \mathrm{Aab}$ \\
\hline \multirow[t]{2}{*}{$\mathrm{HC}$} & $146,0 \mathrm{ABab}$ & $87,7 \mathrm{Bb}$ & $125,5 \mathrm{ABab}$ & $179,6 \mathrm{Aa}$ & $145,0 \mathrm{ABa}$ & $158,0 \mathrm{Aa}$ \\
\hline & \multicolumn{6}{|c|}{ Taxa Fotossintética $-\mathrm{A}\left(\mathrm{mol} \mathrm{m}^{-2} \mathrm{~s}^{-1}\right)$} \\
\hline $\mathrm{TC}^{1 /}$ & $45,1 \mathrm{ABa}$ & $51,2 \mathrm{ABa}$ & $41,3 \mathrm{Ba}$ & $47,9 \mathrm{ABa}$ & $60,7 \mathrm{Aa}$ & $48,0 \mathrm{ABa}$ \\
\hline HA & $37,5 \mathrm{Ab}$ & $25,8 \mathrm{Bb}$ & $36,1 \mathrm{Aa}$ & $28,9 \mathrm{Bb}$ & $37,0 \mathrm{Ab}$ & $37,3 \mathrm{Ab}$ \\
\hline HB & 41,1 Bab & $36,6 \mathrm{Bab}$ & $38,9 \mathrm{Ba}$ & $40,3 \mathrm{Bab}$ & 49,5 Aab & $38,8 \mathrm{Bb}$ \\
\hline $\mathrm{HC}$ & 42,1 Aab & $36,4 \mathrm{Aab}$ & $38,4 \mathrm{Aa}$ & $32,8 \mathrm{Bb}$ & $40,5 \mathrm{Ab}$ & $40,1 \mathrm{Ab}$ \\
\hline
\end{tabular}

1/ TC: testemunha capinada; HA: ametryn $\left(2.000 \mathrm{~g} \mathrm{ha}^{-1}\right)$; HB: trifloxysulfuron-sodium $\left(22,5 \mathrm{~g} \mathrm{ha}^{-1}\right)$; HC: ametryn + trifloxysulfuron-sodium $\left(1.673+37,0 \mathrm{~g} \mathrm{ha}^{-1}\right) .{ }^{2 /}$ Médias seguidas pela mesma letra, maiúscula na linha e minúscula na coluna, dentro de cada variável, não diferem pelo teste de Duncan a $5 \%$ de probabilidade.

relacionado à intensidade fotossintética da planta no momento da avaliação, ou seja, de modo geral, quanto mais acelerado for o metabolismo da planta, maior o consumo de $\mathrm{CO}_{2}$ por unidade de tempo.

Com relação ao fluxo de gases pelos estômatos (U), ele não foi alterado em função dos genótipos avaliados ou dos tratamentos herbicidas aplicados, com valor médio de 199,1 (Tabela 2). Essa característica normalmente é alterada somente quando a planta está sob estresse de déficit hídrico, quando ocorre acentuado aumento da resistência estomática, associado à menor abertura do poro dos estômatos que permanecem abertos (Messinger et al., 2006).

A concentração interna de $\mathrm{CO}_{2}$ do mesofilo foliar (Ci) foi afetada pela aplicação dos herbicidas, com diferenças entre os genótipos avaliados (Tabela 2). De maneira geral, foi observado para essa variável o inverso do obtido para o $\mathrm{CO}_{2}$ consumido, ou seja, os tratamentos envolvendo ametryn, isoladamente ou em mistura com trifloxysulfuron-sodium, apresentaram maior concentração interna de $\mathrm{CO}_{2}$ na folha que a testemunha em todos os genótipos, exceto RB835486, e também maior que o tratamento de trifloxysulfuron-sodium para 
RB867515 e RB947520. A concentração de $\mathrm{CO}_{2}$ no mesofilo foliar foi em torno de $50 \%$ maior nas plantas sob aplicação de ametryn do que na testemunha sem aplicação herbicida. Em razão de o herbicida ametryn inibir a fotossíntese e competir pelos sítios de ação com a proteína $\mathrm{D} 1$, há menor gasto do $\mathrm{CO}_{2}$ que está no mesofilo foliar e, assim, ocorre maior acúmulo, havendo interrupção na cadeia transportadora de elétrons e, consequentemente, na produção de ATP e NADPH, que são usados para a fixação do $\mathrm{CO}_{2}$ (Weller, 2003; Silva et al., 2007). Trifloxysulfuron-sodium também alterou a concentração interna de $\mathrm{CO}_{2}$ na folha, mas de forma menos intensa do que observado no tratamento de ametryn.

A Ci é considerada uma variável fisiológica influenciada por fatores ambientais, como disponibilidade hídrica, luz e energia, entre outros (Ometto et al., 2003). Alguns pesquisadores relatam que a luz afeta indiretamente a abertura estomática através de seu efeito na assimilação de $\mathrm{CO}_{2}$ (Nishio et al., 1994). No entanto, estudos demonstram que a abertura estomática é menos dependente da $\mathrm{Ci}$, respondendo à luz diretamente (Sharkey \& Raschke, 1981). Como neste experimento o déficit hídrico e o sombreamento não foram fatores limitantes ao metabolismo das plantas de cana-de-açúcar, acredita-se que os resultados sejam atribuídos ao efeito de herbicidas no metabolismo.

A taxa fotossintética (A) observada no tratamento com trifloxysulfuron-sodium em todos os genótipos foi similar à da respectiva testemunha sem aplicação dos herbicidas, com exceção de SP80-1816 (Tabela 2). De maneira similar, o tratamento com ametryn isolado mostrou taxa de fotossintese inferior à da testemunha sem aplicação para todos os genótipos, à exceção de RB855113, cujo valor foi similar ao da testemunha sem aplicação herbicida. O tratamento envolvendo a mistura formulada de ametryn + trifloxysulfuronsodium situou-se em posição intermediária entre a testemunha sem aplicação e o tratamento com ametryn isolado para os genótipos RB72454 e RB835486. Para o genótipo RB855113, nenhum tratamento diferiu da testemunha sem aplicação, e para RB867515, RB947520 e SP80-1816, a mistura de herbicidas foi inferior à testemunha e similar ao tratamento de ametryn aplicado isoladamente.
De maneira geral, o genótipo RB835486 foi o que apresentou menor consumo de $\mathrm{CO}_{2}$ sob efeito do ametryn. Esse efeito resultou na menor atividade de fotossíntese desse genótipo quando comparado com a testemunha sem aplicação herbicida (Tabela 2). O genótipo RB947520, por outro lado, esteve entre os que mais consumiram $\mathrm{CO}_{2}$ quando sob tratamento com trifloxysulfuron-sodium, refletindo em menor concentração interna de $\mathrm{CO}_{2}$ no mesofilo foliar neste tratamento e em maior atividade fotossintética (A) que os demais genótipos no mesmo tratamento.

Os resultados obtidos estão de acordo com os observados por Corniani et al. (2006), ao constataram que nas plantas de girassol submetidas a estresse a taxa de fotossintese diminuiu enquanto a concentração de $\mathrm{CO}_{2}$ na cavidade subestomática ( $\mathrm{Ci}$ ) aumentou concomitantemente.

De modo geral, foi possivel inferir que, embora os danos causados pelo ametryn sobre as plantas de cana-de-açúcar sejam mais evidentes que os ocasionados pelo trifloxysulfuron-sodium em função de seu mecanismo de ação, variações em decorrência da aplicação do último também podem ser efetivamente avaliadas pelos danos indiretos ao mecanismo fotossintético. Conclui-se que os genótipos de cana-de-açúcar avaliados apresentaram sensibilidade diferencial aos referidos herbicidas. Isso evidencia a necessidade de levar em consideração o genótipo cultivado e a escolha do herbicida a ser utilizado para controle de plantas daninhas na cultura da cana-de-açúcar.

\section{AGRADECIMENTOS}

Ao Conselho Nacional de Desenvolvimento Científico e Tecnológico (CNPq-Brasil), pela concessão de bolsas.

\section{LITERATURA CITADA}

ANDREOLI, C.; DE SOUZA, S. P. Cana-de-açúcar: a melhor alternativa para conversão da energia solar e fóssil em etanol. Econ. Energia, v. 2, n. 59, p. 27-33, 2006.

AZANIA, C. A. M. et al. Seletividade de herbicidas. II Aplicação de herbicidas em pós-emergência inicial e tardia da cana-de-açúcar na época das chuvas. Planta Daninha, v. 23, n. 4, p. 669-675, 2006. 
BARELA, J. F.; CHRISTOFFOLETI, P. J. Seletividade de herbicidas aplicados em pré-emergência da cultura da cana-deaçúcar (RB867515) tratada com nematicidas. Planta Daninha, v. 24, n. 2, p. 371-378, 2006.

COMISSÃO DE FERTILIDADE DO SOLO DO ESTADO DE MINAS GERAIS - CFSEMG. Recomendações para o uso de corretivos e fertilizantes em Minas Gerais - 5a aproximação. Viçosa, MG: Universidade Federal de Viçosa, 1999. $359 \mathrm{p}$.

CHRISTOFFOLETI, P. J. et al. Carfentrazone-ethyl aplicado em pós-emergência para o controle de Ipomoea spp. e Commelina benghalensis na cultura da cana-de-açúcar. Planta Daninha, v. 24, n. 1, p. 83-90, 2006.

CORNIANI, N. et al. Determinação das trocas gasosas e de potencial hídrico através do uso de sistemas portáteis na avaliação do estresse. In: SIMPÓSIO INTERNACIONAL DE INICIAÇÃO CIENTÍFICA DA UNIVERSIDADE DE SÃO PAULO, 14., 2006, Piracicaba. Anais... São Paulo: USP, 2006. CD-ROM.

\section{EMPRESA BRASILEIRA DE PESQUISA}

AGROPECUÁRIA - EMBRAPA. Centro Nacional de Pesquisa Agropecuária de Solos. Sistema brasileiro de classificação de solos. Rio de Janeiro: 2006. 412 p.

EMPRESA BRASILEIRA DE PESQUISAAGROPECUÁRIA - EMBRAPA. Disponível em: <http://www.embrapa.gov.br/ noticias/artigos/>. Acesso em: 10 jul. 2008.

FERREIRA, E. A. et al. Sensibilidade de cultivares de cana-de-açúcar à mistura trifloxysulfuron-sodium + ametryn. Planta Daninha, v. 23, n. 1, p. 93-99, 2005

KIRSCHBAUM, M. U. F.; PEARCY, R. W. Gas exchange analysis of the relative importance of stomatal and biochemical factors in phosynthetic induction in Alocasia macrorrhiza. Plant Physiol., v. 86, n. 3, p. 782-785, 1988.

KUVA, M. A. et al. Períodos de interferência das plantas daninhas na cultura da cana-de-açúcar. III - Capim-brachiaria (Brachiaria decumbens) e capim-colonião (Panicum maximum). Planta Daninha, v. 21, n. 1, p. 37-44, 2003.

KUVA, M. A. et al. Padrões de infestação de comunidades de plantas daninhas no agroecossistema de cana-crua.

Planta Daninha, v. 26, n. 3, p. 549-557, 2008.

LORETO, F.; BONGI, G. Combined low temperature-high light effects on gas exchange properties of jojoba leaves. Plant Physiol., v. 91, n. 4, p. 1580-1585, 1989

MESSINGER, S. M. et al. Evidence for involvement of photosynthetic processes in the stomatal response to $\mathrm{CO}_{2}$. Plant Physiol., v. 140, n. 2, p. 771-778, 2006.
NAVES-BARBIERO, C. C. et al. Fluxo de seiva e condutância estomática de duas espécies lenhosas sempre-verdes no campo sujo e cerradão. R. Bras. Fisiol. Veg., v. 12, n. 2, p. 119-134, 2000.

NEGRISOLI, E. et al. Seletividade de herbicidas aplicados em pré-emergência na cultura da cana-de-açúcar tratada com nematicidas. Planta Daninha, v. 22, n. 4, p. 567-575, 2004.

NISHIO, J. N.; SUN, J.; VOGELMANN, T. C. Photoinhibition and the light environment within leaves. In: BAKER, N. R.; BOWYER, J. R. (Eds.) Photoinhibition of photosynthesis. Oxford: BIOS Scientific Publishers, 1994. p. $1-24$.

OLIVEIRA, R. A. et al. Crescimento e desenvolvimento de três cultivares de cana-de-açúcar, em cana-planta, no Estado do Paraná. Sci. Agr., v. 5, n. 1-2, p. 87-94, 2004.

OMETTO, J. P. H. B. et al. Variação temporal do isótopo estável do carbono em material arbóreo em florestas da região Amazônica. In: CONGRESSO BRASILEIRO DE ECOLOGIA, 4., 2003, Fortaleza. Anais... Rio Claro: Sociedade de Ecologia do Brasil, 2003. CD-ROM.

REIS, M. R. et al. Dinâmica de nutrientes em tecidos foliares de cana-de-açúcar após aplicação de herbicidas.

Planta Daninha, v. 26, n. 1, p. 175-184, 2008.

RODRIGUES, B. N.; ALMEIDA, F. S. Guia de herbicidas. 5.ed. Londrina: 2005. 592 p.

SHARKEY, T. D.; RASCHKE, K. Effect of light quality on stomatal opening in leaves of Xanthium strumarium L. Plant Physiol., v. 68, n. 5, p. 1170-1174, 1981.

SILVA, A. A. et al. Herbicidas: classificação e mecanismo de ação. In: SILVA, A. A.; SILVA, J. F. (Eds.). Tópicos em manejo de plantas daninhas. Viçosa, MG: Universidade Federal de Viçosa, 2007. p. 83-148.

SISTEMA DE AGROTÓXICOS FITOSSANITÁRIOS AGROFIT. Disponível em: <http://extranet.agricultura.gov.br/ agrofit>. Acesso em: 19 de set. de 2008

TAIZ, L.; ZEIGER, E. Plant physiology. Sunderland: Sinauer, 2006. 705 p.

VELINI, E. D. et al. Avaliação da seletividade da mistura de oxyfluorfen e ametryne, aplicada em pré e pós-emergência, a dez variedades de cana-de-açúcar (cana planta). Planta Daninha, v. 18, n. 2, p. 123-134, 2000

WELLER, S. Photosystem II inhibitors. In: Herbicide action course. West Lafayette: Purdue University, 2003. p. $131-184$ 